NASA Technical Memorandum 106220

AIAA-93-2402

\title{
Gravity Sensitivity of a Resistojet Water Vaporizer
}

\section{W. Earl Morren \\ Lewis Research Center \\ Cleveland, Ohio}

Prepared for the

29th Joint Propulsion Conference and Exhibit cosponsored by the AIAA, SÄE, ASME, and ASEE

Monterey, California, June 28-30, 1993 

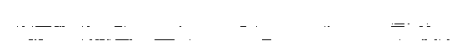

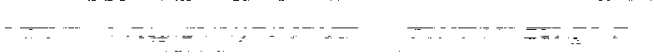

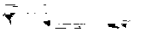

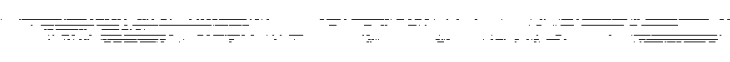

$\cdots$

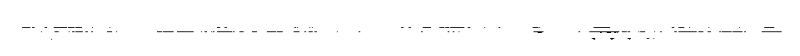

$=-1 .-$

$\because=$

$-=$

$-=\cdots+\cdots+\cdots$

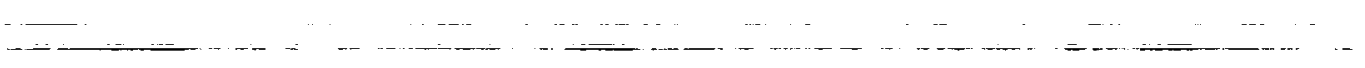

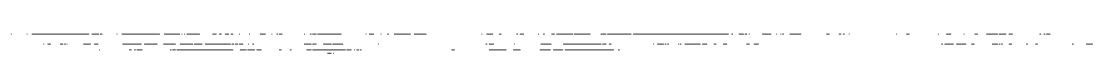




\title{
Gravity Sensitivity of a Resistojet Water Vaporizer \\ W. Earl Morren \\ National Aeronautics and Space Administration \\ Lewis Research Center \\ Cleveland, $\mathrm{OH}$
}

\begin{abstract}
A laboratory model of a water vaporizer for resistojet applications was designed, fabricated, and steady and transient characteristics were measured. Vaporizer operation was not impacted by rotation about a horizontal axis normal to its own. The vaporizer was operated under low and high accelerations aboard a jet aircrafi for periods up to $25 \mathrm{~s}$ at flow rates ranging from $150 \times 10^{-6}$ to $230 \times 10^{-6} \mathrm{~kg} / \mathrm{s}$. Slight changes in inlet and outlet pressures and some heat exchanger temperatures were observed during the low-gravity tests. However, the results of these tests indicated probable compatibility of the vaporizer design tested with a low-gravity environment.
\end{abstract}

\section{INTRODUCTION}

Resistojets using water propellant have been considered for stationkeeping several times during the past three decades. Biowaste resistojets, for which water was a candidate propellant, were baselined on the Manned Orbital Research Laboratory (MORL) during the late $1960{ }^{\prime} \mathrm{s}^{1}$, and water resistojets were baselined for orbit maintenance on the Industrial Space Facility (ISF) during the late 1980 's $\mathrm{s}^{2}$. Water was also a candidate propellant for multipropellant resistojets baselined for growth versions of Space Station Freedom (SSF).

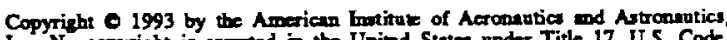
boc. No copyrient is surted in the Unied Stutes under Title 17. U.S. Code.

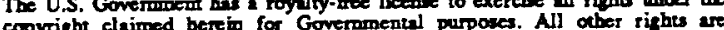
reperved by the copyright owner.
Recent emphasis on reducing SSF life cycle costs have renewed interest in water resistojets. A recent study predicted substantial benefits to SSF propulsion logistics from shifting orbit maintenance duties from the baseline high-thrust hydrazine system to water resistojets ${ }^{3}$. These benefits were derived from a combination of the potential availability of up to $1800 \mathrm{~kg} / \mathrm{yr}$ excess water aboard SSF and a more favorable propellant mass fraction for water launched in place of hydrazine. The Ref. 3 study considered the cost of propellant launch, estimated at about $\$ 2300 / \mathrm{kg}$, and the cost of ground processing of the baseline hydrazine propulsion modules, which was on the order of $\$ 4500 / \mathrm{kg}$ launched. 
Resistojets operating on water differ from gas-fed thrusters in that the liquid must be vaporized prior to being expelled through the nozzle. Expansion of liquid water to a vacuum can lead to nozzle clogging by ice and subsequent thruster failure. Water resistojets therefore require vaporizers capable of operation in the low-gravity environment on orbit.

Technology conducted in support of the MORL program ${ }^{4}$ focused on a vaporizer employing a packed-bed heat exchanger intended for use with a $0.1 \mathrm{~N}$ biowaste resistojet at flow rates up to $50 \times 10^{-6} \mathrm{~kg} / \mathrm{s}$. Operation of the vaporizer alone and integrated with a resistojet was stable in various orientations with respect to gravity, which was believed to indicate compatibility with a low-gravity environment. The results of the efforts described in Ref. 4 showed that a packed bed design could be suitable for resistojet applications, but some means of automatic power control would be required. The Ref. 4 vaporizer was later redesigned to operate at flow rates up to $250 \times 10^{-6} \mathrm{~kg} / \mathrm{s}$ and was equipped with an outlet temperature feedback power controller ${ }^{5}$. No data evaluating gravity sensitivity were reported in Ref. 5.

A water resistojet employing vortical flow for phase separation was investigated in support of the ISF $^{6}$. This device demonstrated integral vaporization and superheating. A heater temperature feedback power controller ${ }^{7}$ was subsequently implimented. Unpublished results of later tests found the Ref. 6 vaporizer to be highly sensitive to orientation with respect to gravity.

A more recent water vaporizer technology effort revisited the packed bed configuration $^{8}$. The steady performance of a vaporizer filled with sand was measured over a range of flow rates of interest for resistojet applications. Power was modulated to regulate the ratio of power to mass flow rate (i.e., specific power). Flow rates and outlet temperatures and pressures of this vaporizer were found to be insensitive to orientation with respect to gravity. The vaporizer operated steadily when tested alone and when integrated with a resistojet at flow rates above $50 \times 10^{-6}$ and $120 \times 10^{-6} \mathrm{~kg} / \mathrm{s}$, respectively, although flow oscillations were observed below these values. The relative pressure drops within the water feed system and vaporizer heat exchanger were identified as the causes of the oscillations.

Previous efforts have demonstrated the capability to vaporize water in a controlled manner at flow rates of interest for resistojet applications in various orientations with respect to gravity. Feed systems similar to those used to feed hydrazine thrusters in flight applications have been applied to water resistojets in 
ground tests. Options for vaporizer power control, including outlet temperature, heater temperature, and specific power regulation have been demonstrated. However, no validations of water vaporizer life have been conducted, and the question remained as to whether insensitivity to orientation with respect to gravity in ground tests equates to low-gravity compatibility.

This paper addresses the latter issue of lowgravity compatibility of a packed-bed water vaporizer. A water vaporizer was designed and built which addressed issues of pressure drop exposed in Ref. 8. Diagnostics were incorporated to evaluate temperature and pressure distributions. Steady and transient characteristics and sensitivity to orientation with respect to gravity of the new design were measured in ground tests. Low-gravity behavior was examined aboard a jet aircraft flying parabolic trajectories. Details of the upgraded design and results of the tests conducted are presented, as are recommendations for further design improvement.

\section{APPARATUS AND PROCEDURE}

\section{Vaporizer}

Previous tests ${ }^{8}$. showed that flow rates and outlet temperatures and pressures of a water vaporizer filled with sand were not sensitive to orientation with respect to gravity, which was believed to be an indication of compatibility with a lowgravity environment. Several problems became apparent with the first version, however, during the tests reported in Ref. 8. The ratio of length to flow area (L/A) for the heat exchanger was nearly $450 \mathrm{~cm}^{-1}$, and pressure drops as high as $800 \mathrm{kPa}$ were measured. When combined with the pressure drop through a fluid resistor, used to decouple the feed system from the vaporizer, the system required a feed pressure of nearly $3.9 \mathrm{MPa}$ to produce a flow rate of $174 \times 10^{-6} \mathrm{~kg} / \mathrm{s}$. The ratio of fluid resistor-to-vaporizer pressure drops ranged from 0.13 to 0.33 , so the effects of changes in vaporizer pressure drop were not attenuated sufficiently by the presence of the fluid resistor. System instabilities at low flow rates resulted. Temperature drops between the heater and heat exchanger, which ranged from 400 to $550^{\circ} \mathrm{C}$, were deemed excessive. The heat exchanger configuration was not conducive to instrumentation with thermocouples, which precluded investigation of internal responses to changes in gravitational environment.

The goals for the current vaporizer design were to reduce the vaporizer pressure drop substantially, to reduce the heater-to-heat exchanger temperature drop, and to facilitate instrumentation for temperature and pressure mapping. The heat exchanger was also designed to accept a variety of porous media, although only tests of a 
sand-filled version are reported herein. Sand was chosen for the heat exchanger packing because of its ability to wick liquid, its ready availability, and the ease with which it would fill irregular heat exchanger paths. Preliminary tests of a vaporizer filled with sintered metal are presented in a companion paper 9 . Flow rates of interest ranged from $100 \times 10^{-6}$ to $250 \times 10^{-6} \mathrm{~kg} / \mathrm{s}$, since these would produce thrust levels bracketing likely resistojet applications. Corresponding power levels ranged from 300 to $750 \mathrm{~W}$. Vaporizer outlet pressures of 200 to $500 \mathrm{kPa}$ would be required to feed resistojets over this range of operating conditions. Outlet temperature was not considered critical as long as the vaporizer exhaust was slightly superheated (i.e., 50 to $100{ }^{\circ} \mathrm{C}$ above saturation).

Figure 1 shows a sectional view of the water vaporizer. The overall configuration consisted of a centrally-located heater surrounded by an annular heat exchanger filled with sand. This configuration was chosen because it was simple to fabricate and assemble, allowed access to the heat exchanger for temperature measurements, and because the majority of heat dissipated by the heater had to travel through the water which tended to minimize thermal losses. The sand used was sandblast-grade 52- to 70-mesh. Liquid was fed to the vaporizer through four $1.6 \mathrm{~mm}$ o.d. tubes evenly spaced about the annulus. A circular channel of $1.6 \mathrm{~mm}$ square cross section on the inside of the inlet end cap aided distribution of the incoming liquid about the annulus. A filter made from sintered stainless steel with a $5 \mu \mathrm{m}$ pore size (chosen for convenience) prevented sand from blocking the feed tubes. The heater was a commercially-available unit $102 \mathrm{~mm}$ long by $12.7 \mathrm{~mm}$ dia. rated at $750 \mathrm{~W}$ at 120 $\mathrm{V}$, and was comprised of a nickelchromium alloy filament, ceramic insulation, and inconel sheath. A Type- $K$ thermocouple ( $T_{h}$ in Fig. 1) was embedded in the insulation on axis at the center of the heater cartridge. Four banks of three Type$\mathrm{K}$ thermocouples each $\left(T_{b 1}\right.$ through $T_{b 12}$ in Fig. 1) were located in line with the liquid inlets with junctions located at the radial midpoint of the annulus. The heat exchanger shell was made from stainless steel tubing $102 \mathrm{~mm}$ long with $25.4 \mathrm{~mm}$ o.d. and $1.65 \mathrm{~mm}$ wall thickness. Superheated vapor exited the heat exchanger through an outlet tube $41 \mathrm{~mm}$ long with $12.7 \mathrm{~mm}$ o.d. and $7.95 \mathrm{~mm}$ i.d. A sintered stainless steel filter contained the sand at the end of the outlet tube. The outlet tube was filled with sand because the outlet filter had to be located at the end of the outlet tube to allow repacking of the heat exchanger, if necessary. Thus the flow restriction within the sand-filled heat exchanger consisted of an annulus in series with a tube with $\mathrm{L} / \mathrm{A}$ of 3.84 and $8.34 \mathrm{~cm}^{-}$ 1 , respectively, for a total of $12.2 \mathrm{~cm}^{-1}$. This should have resulted in a heat 
exchanger pressure drop 97 percent lower than the Ref. 8 vaporizer, based solely on the relative L/A. The heat exchanger was filled through the outlet tube after the thermocouple probes were inserted. The heat exchanger was rotated and vibrated during filling to assure no voids formed in the sand. The volume of sand added was compared to the estimated heat exchanger volume to further ensure it was full.

\section{Test Apparatus}

Figures 2 and 3 show a schematic diagram and photo of the test apparatus, respectively. The vaporizer, feed system, power control unit, and data acquisition system were fully contained in two small instrument racks for integration with the aircraft. Liquid was fed to the vaporizer from a reservoir with a piston and $\mathrm{O}$-ring. The flow rate through the system was changed by adjusting the pressure applied to the accumulator from a regulated gas supply. The flow rate was determined by measuring the pressure drop of the water flowing through a commercially-available fluid resistor. Ideally, the pressure drop across this fluid resistor should be large relative to the vaporizer pressure drop, so that the effects of pressure fluctuations within the heat exchanger are attenuated as they propagate upstream into the feed system. This was not the case in the Ref. 8 work, and system instabilities were observed at low flow rates. The same fluid resistor was used in the current work as in the Ref. 8 work, so the substantially lower pressure drop of the current vaporizer design yielded a much more favorable fluid resistor to heat exchanger pressure drop ratio. The pressure of the liquid feedwater was measured between the fluid resistor and the vaporizer. The vaporizer exhausted into a small plenum where effluent pressure and temperature were measured. An orifice $0.74 \mathrm{~mm}$ in diameter simulated a resistojet.

Power was provided to the heater during aircraft tests by a rectifier and power control unit which converted the $400 \mathrm{~Hz}$, $115 \mathrm{Vac}$ aircraft bus power into $160 \mathrm{Vdc}$, pulsed at $400 \mathrm{~Hz}$. The duty cycle of the pulsed dc was modulated to maintain the ratio of power to mass flow rate (referred to herein as specific power) approximately constant at $3.0 \mathrm{MJ} / \mathrm{kg}$. During ground tests the rectifier was replaced by a laboratory $\mathrm{dc}$ power supply which fed the power control unit with $125 \mathrm{Vdc}$ (not shown in Fig. 2).

Test conditions were monitored and heater power was controlled using a microcomputer-based data acquisition and control system (DACS). Table I summarizes the parameters monitored.

\section{Vaporizer Tests}

Steady state and transient characteristics were measured in ground tests with the vaporizer mounted in a vertical-axis position with the inlet at the top. Feed 
pressures of $680,1360,2040$, and 2720 $\mathrm{kPa}$ provided flow rates spanning the desired range. The cold vaporizer was started full of water (i.e., flooded) with feed pressure and specific power regulated at $680 \mathrm{kPa}$ and $3.0 \mathrm{MJ} / \mathrm{kg}$, respectively. This starting method was necessary because a facility to evacuate the vaporizer between starts was not available and because flowing water through the vaporizer was a convenient method of cooling between test series. As steady operation was achieved at each operating condition the feed pressure was increased by $680 \mathrm{kPa}$ to reach the next operating condition. This provided both steady performance and responses to step increases of feed pressure. Operating conditions were recorded every $2 \mathrm{~s}$ during these tests. Thermal efficiency, defined as the increase in fluid enthalpy within the vaporizer divided by the input specific power, was calculated based on the pressures and temperatures measured at the inlet and outlet. Fluid enthalpies were obtained from published steam tables ${ }^{10}$.

Tests presented in Ref. 8 examined the sensitivity of the vaporizer tested to orientation with respect to gravity because this was believed to give some insight into the low-gravity compatibility of that vaporizer. In an effort to validate that assumption, the sensitivity of the current vaporizer design to orientation with respect to gravity was examined in ground tests for comparison to subsequent low-gravity tests in an aircraft. The vaporizer was started cold and flooded at feed pressures of 680 , 1360,2040 , and $2720 \mathrm{kPa}$ in a vertical-axis position with the liquid fed to the top (upright position). The vaporizer was rotated $90^{\circ}$ about a horizontal axis normal to its own every $15 \mathrm{~min}$ to horizontal and inverted positions before being returned to the upright position. This provided sufficient time for the vaporizer to reach steady operation in each position before being moved to the following position. Operating conditions were recorded every 2 $s$ during these tests.

Low-gravity tests of the vaporizer were conducted by flying parabolic trajectories aboard a jet aircraft (see Figure 4). Accelerations experienced by the vaporizer progressed from about $1 \mathrm{~g}$ (gravitational acceleration at sea level) to as much as $3 \mathrm{~g}$ during the initial pull-up maneuver (about $15 \mathrm{~s}$ long), then to less than $0.02 \mathrm{~g}$ during the low-gravity segment ( 20 to $25 \mathrm{~s}$ ), then into the second pull-up (typically 20 to $30 \mathrm{~s}$ long) and finally back to $1 \mathrm{~g}$. The vaporizer was mounted in a vertical-axis position with the liquid inlet at the top. The vaporizer was started prior to take-off and allowed to reach steady state at a feed pressure and specific power of approximately $1360 \mathrm{kPa}$ and $3.0 \mathrm{MJ} / \mathrm{kg}$, repectively, prior to the first parabolic trajectory. Additional trajectories were flown with the vaporizer operating steadily 
at feed pressures of 2040 and $2720 \mathrm{kPa}$, again with specific power regulated at 3.0 $\mathrm{MJ} / \mathrm{kg}$. Low-gravity characteristics were not observed at the $680-\mathrm{kPa}$ point (flow rate of $100 \times 10^{-6} \mathrm{~kg} / \mathrm{s}$ ) because aircraft fuel supply limitations did not allow sufficient time to complete four trajectories plus the loitering time necessary for the vaporizer to equilibrate at each new flow rate.

\section{RESULTS AND DISCUSSION}

The objectives of this work were to characterize the performance of a packedbed water vaporizer and to investigate its sensitivity to acceleration at flow rates of interest for resistojet applications. The first step was to measure its steady and transient characteristics in ground tests. For these tests the vaporizer was mounted in a vertical-axis position with the inlet at the top. Then the vaporizer was operated in various positions to expose any sensitivities to orientation with respect to gravity. Finally, the operating vaporizer was exposed to brief periods of low acceleration $(<0.02 \mathrm{~g})$ aboard a jet aircraft. During the parabolic trajectories flown to produce the low accelerations the vaporizer was exposed to relatively high accelerations ( 2.5 to $3.0 \mathrm{~g}$ ) immediately prior to and following the low-gravity test segments. Thus operation was observed at accelerations ranging from $-1 \mathrm{~g}$ to nearly 3 $\mathrm{g}$ (relative to the baseline vertical-axis, inlet up orientation) during the test program. The following discussion describes the steady and transient characteristics, as well as the vaporizer responses to rotation about a horizontal axis in a 1-g environment and to the accelerations experienced during the parabolic trajectories.

Steady and Transient Characteristics Ground Tests

Figure 5 shows the variations in steady state pressure drop, outlet temperature and pressure, and saturation temperature corresponding to the outlet pressure over the range of flow rates tested (these data are summarized in Table II). The vapor produced was superheated at all flow rates. The 28 percent increase in outlet temperature over the range of flow rates tested was due primarily to the increase in outlet pressure. However, some of the increase was attributable to increased outlet enthalpy, which rose about 9 percent. The increase in outlet enthalpy was due to increased heat transfer efficiency, which ranged from 0.93 to 0.98 , and a slight increase in specific power input with flow rate. Specific power input increased approximately 3 percent due to control errors introduced in the algorithm used by the DACS to modulate heater power (power control was open-loop, thus no error correction was made).

The heat exchanger pressure drop occurred in three distinct regions: the annulus; the outlet tube; both packed with sand; and the 
sintered stainless steel outlet filter. The pressure drop of the incoming liquid across the inlet filter was small compared to the total vaporizer pressure drop. Comparison of pressure drops using the sintered metal filter with results of diagnostic tests using a stacked-screen filter showed that approximately 47 percent of the overall pressure drop was concentrated in the outlet filter. A calibration of heat exchanger pressure drop versus flow rate of cold nitrogen gas indicated that, of the pressure drop within the sand-packed portion of the heat exchanger, approximately 16 percent was lost within the annulus; the remaining 84 percent was lost within the outlet tube. These results suggested two design changes for subsequent sand-packed water vaporizers. First, the sintered metal filter should be replace by a stack of screens. The stacked-screen filter used in the diagnostic tests consisted of four layers 5mesh stainless steel, stacked with staggered grid orientations, plus one layer 50-mesh stainless steel screen inserted between the middle two layers of heavier screen. This assembly had no significant pressure drop. Second, the outlet tube region of the sand bed should be eliminated by enlarging the diameter of the outlet filter and relocating it close to the outlet end of the heater. These changes would reduce the vaporizer pressure drop from the 140 to $550 \mathrm{kPa}$ observed to about $50 \mathrm{kPa}$ at a flow rate of $235 \times 10^{-6} \mathrm{~kg} / \mathrm{s}$.
Brief tests at flow rates of about $50 \times 10^{-6}$ $\mathrm{kg} / \mathrm{s}$ were conducted to expose instabilities, such as were reported for low-flow rate operation in Ref. 8. None were observed due to the more favorable ratio of fluid resistor-to-heat exchanger pressure drops for the current system. This ratio increased with flow rate from 2.3 to 6.8 in the current tests, as compared to 0.13 to 0.33 during the Ref. 8 tests. The same fluid resistor was used for both test series; the differences in pressure drop ratios were due to a substantially lower vaporizer pressure drop in the current tests. This indicates that a less-restrictive fluid resistor could be employed with the current vaporizer without compromising stability at low flow rates. For example, a vaporizer modified as previously described to reduce pressure drop could be combined with a fluid resistor sized to produce a pressure drop of $150 \mathrm{kPa}$ at $235 \times 10^{-6} \mathrm{~kg} / \mathrm{s}$. The system pressure drop would then be $200 \mathrm{kPa}$, as compared to more than $2200 \mathrm{kPa}$ for the current system. A resistojet operating at this flow rate at a specific impulse of $235 \mathrm{~s}$ would produce about $0.5 \mathrm{~N}$ of thrust and require an outlet pressure of approximately 500 to $700 \mathrm{kPa}$ from the vaporizer. The water reservoir (feed) pressure required for such a system (including fluid resistor, vaporizer and resistojet) would be 700 to $900 \mathrm{kPa}$. 
Figures $6 \mathrm{a}$ through $6 \mathrm{~d}$ show the variations in twelve heat exchanger temperatures with flow rate. Each figure shows three temperatures in one of four axial rows of thermocouples, as well as the estimated saturation temperature within the heat exchanger annulus. The saturation temperatures shown are those corresponding to the measured vaporizer inlet pressures. This was deemed reasonable because of a relatively low pressure drop through the annular portion of the heat exchanger. Bed temperatures at midpoint (Bed Temperatures \#2, \#5, \#8, and \#11) were azimuthally uniform to within $3{ }^{\circ} \mathrm{C}$ and were typically 4 to $7^{\circ} \mathrm{C}$ higher than estimated saturation temperatures. Temperatures near the inlet (Bed Temperatures \#1, \#4, \#7, and \#10) varied from subcooled to saturated depending on flow rate and azimuthal location. This indicated that most of the heat required to bring the incoming liquid to saturation temperature - about 13 percent of the total input energy - was added in the inlet filter region. Transition from saturated to subcooled occured as flow rate increased, if at all, due to the increased cooling of the inlet region. Three temperatures near the annulus exit (Bed Temperatures \#6, \#9, and \#12) were superheated at all times, though not uniform; Bed Temperature \#3 was always saturated. These results indicated a nonuniform pattern of dry-out (i.e., the point at which all liquid has been vaporized) within the heat exchanger.

Transient behavior was examined by observing vaporizer responses to step increases in feed pressure. Typical response of the flow rate, outlet temperature, and inlet and outlet pressures to such a perturbation are shown in Figure 7. Responses of three representative heat exchanger temperatures are shown in Fig. 8. These figures show that the time required for the vaporizer to re-establish equilibrium following perturbation ranges from about one minute for system pressures and upstream heat exchanger temperatures to several minutes for downstream heat exchanger and outlet temperatures. These equilibration times are significantly longer than the sub-minute low-gravity test periods available aboard the aircraft. However, many of the parameters monitored responded quickly enough to indicate trends during the short low-g test segments.

Sensitivity to Orientation with Respect to Gravity - Ground Tests

Figure 9 shows the histories of the mass flow rate, outlet temperature, and inlet and outlet pressures as the vaporizer was rotated about a horizontal axis normal to its own. The flow rate and outlet pressure showed no long-term sensitivity to orientation, although brief perturbations to outlet pressure were observed. Inlet 
pressure did increase slightly during the test, most probably as a result of the gradual increase in downstream heat exchanger temperatures (see Fig. 10). Upstream heat exchanger temperatures also showed some sensitivity to orientation, decreasing some 10 to $20^{\circ} \mathrm{C}$ as the vaporizer was inverted from the verticalaxis inlet-up position. This effect indicates that liquid was pulled from the central part of the annulus back toward the inlet as the vaporizer was inverted. Still, the observed impacts on vaporizer behavior were relatively small and gradual. At no time were any instabilities noted.

Sensitivity to Acceleration - Aircraft Tests

Figure 11 shows the mass flow rate, inlet and outlet pressures, outlet temperature, and net acceleration (i.e., the vector sum of the $x-, y-$, and $z$-axis accelerations) through one parabolic trajectory. The inlet and outlet pressures increased slightly above nominal (1-g) values during the high-acceleration pull-ups, but decreased to about 5 percent below nominal during the low-gravity test segment. These pressures varied less than 1 percent after reaching their minimum values during the low-gravity segment. The relative impacts on inlet and outlet pressures were approximately 10 and 3 percent at the lowest and highest flow rates tested, respectively. The measured flow rate showed no response to acceleration, but it is important to remember that this measurement was remote from the vaporizer. The indicated pressure drop across the vaporizer varied, so it is reasonable to assume that the actual flow rate through the vaporizer was impacted (i.e., mass was accumulated or depleted within the vaporizer). The long-term impact on vaporizer pressure drop (and thus flow rate) and temperature distribution could not be assessed due to the short durations of the low-gravity conditions. The outlet temperature was not affected. Figure 12 shows profiles of three heat exchanger temperatures through a parabolic trajectory. Perturbations to the bed temperatures nearest the inlet and outlet of 2 to 3 percent were observed. These traces are representative of the responses from the four banks of thermocouples to the changing accelerations. Although the heat exchanger temperatures appeared to reach steady values during the low-gravity test segment, it is important to recall from the gravity sensitivity ground tests (Figs. 9 and 10) that final values of heat exchanger temperatures were not reached for several minutes following changes in orientation. Additional changes to temperature distributions could be expected if lowgravity conditions were maintained for longer periods. These data suggest compatibility of the design tested with a low-gravity environment. However, the results are not conclusive due to the relatively long time constant of the 
vaporizer compared to the low-gravity test segments available from the aircraft.

\section{CONCLUDING REMARKS}

A packed-bed water vaporizer designed for resistojet applications was built and tested. Liquid was fed to the vaporizer from a pressurized reservoir and power was modulated to maintain the ratio of power to mass flow rate at approximately $3.0 \mathrm{MJ} / \mathrm{kg}$. Operation in a 1-g environment was stable and predictable at flow rates ranging from $100 \times 10^{-6}$ to $235 \times 10^{-6} \mathrm{~kg} / \mathrm{s}$, yielding superheated vapor at pressures and temperatures of 200 to $550 \mathrm{kPa}$ and 160 to $280{ }^{\circ} \mathrm{C}$, respectively. Thermal efficiencies ranged from 0.93 to 0.98 .

Estimates of the relative contributions of the various sections of the heat exchanger showed that substantial reductions in vaporizer pressure drop could be realized by replacing the outlet filter with a screen and eliminating the long, small diameter, sand-packed outlet tube. Consequently, a less restrictive fluid resistor could be used upstream of the vaporizer, resulting in a substantially lower system pressure drop and allowing lower system feed pressures, with all of the associated savings in system mass.

The vaporizer operated stably in various orientations with respect to gravity in ground tests. Inlet pressure and heat exchanger temperatures near the inlet and outlet were impacted by changes in orientation. However, all observed responses were small compared to nominal values.

Low-gravity testing of the vaporizer was conducted aboard a jet aircraft. Perturbations to vaporizer operation induced by the wide range of accelerations experienced during the parabolic trajectories were minimal. The measured inlet and outlet pressures fluctuated 3 to 10 percent in response to changes in acceleration, with the greatest influence observed at the lowest flow rate during the highest accelerations. Slight disturbances in heat exchanger temperatures were also observed. These results indicate probable compatibility of the vaporizer design tested with a lowgravity environment.

\section{ACKNOWLEDGMENTS}

The author gratefully acknowledges the contributions of Kevin L. Blake, Robert F. Roman, and Eric S. Neumann of the NASA Lewis Research Center for their assistance in preparing the aircraft test hardware and facilitating the test flights. Special thanks to the many members of NASA Lewis' Aircraft Maintenance and Aircraft Operations Branches whose efforts were essential to the completion of this work. 


\section{REFERENCES}

1. Greco, R. V., et al., "Development of

a Biowaste Resistojet Propulsion System Propellant Management and Control System," AIAA 72-448, April 1972.

2. Louviere, A. J., et al., "WaterPropellant Resistojets for ManTended Platforms," IAF-87-259, October 1987.

3. Zimmermann, F. and France, C., "Secondary Propulsion System Options for Space Station Freedom," AIAA 92-3852, July 1992.

4. Phillips, D. G., "Technology Development of a Biowaste Resistojet, Volume 2," NASA CR112150, June 1972.

5. Anon., "Development of a Water Vaporizer for Resistojet Applications: Final Report," The Marquardt Company Report S1244, November 1972.

6. Morren, W. E. and Stone, J. R., "Development of a Liquid-Fed Water Resistojet," AIAA 88-3288, July 1988.
7. Gruber, R. P., "DC Power Control for a Liquid-Fed Resistojet," IEPC 88-045, October 1988.

8. Morren, W. E., "Preliminary Characterizations of a Water Vaporizer for Resistojet Applications," AIAA 93-3533, July 1992.

9. Morren, W. E. and MacRae, G. S.,"Preliminary Endurance Tests of Water Vaporizers for Resistojet Applications," AIAA 93-2403, June 1993.

10. Keenan, J. H., et al, Steam Tables, John Wiley and Sons, New York, 1969. 


\section{Table I. Vaporizer Operating Parameters Monitored}

\begin{tabular}{|c|c|c|}
\hline Parameter & Symbol & Technique \\
\hline Voltage, $\mathrm{V}$ & $\mathrm{V}_{\mathrm{h}}$ & Voltage Divider \\
\hline Current, A & $\mathrm{I}_{\mathbf{h}}$ & Hall-Effect Probe \\
\hline Feed Pressure, $\mathrm{kPa}$ & $P_{f}$ & $\begin{array}{l}\text { Capacitance Pressure } \\
\text { Transducer }\end{array}$ \\
\hline Fluid Resistor Pressure Drop, $\mathrm{kPa}$ & $\Delta \mathrm{P}$ & $\begin{array}{l}\text { Strain Gauge Pressure } \\
\text { Transducer }\end{array}$ \\
\hline Inlet Pressure, $\mathrm{kPa}$ & $\mathbf{P}_{\mathrm{i}}$ & $\begin{array}{l}\text { Capacitance Pressure } \\
\text { Transducer }\end{array}$ \\
\hline Inlet Temperature, ${ }^{\circ} \mathrm{C}$ & $\mathrm{T}_{\mathbf{i}}$ & Type K Thermocouple \\
\hline Heater Temperature, ${ }^{\circ} \mathrm{C}$ & $\mathrm{T}_{\mathrm{h}}$ & Type K Thermocouple \\
\hline Inlet Bed Temperatures, ${ }^{\circ} \mathrm{C}$ & $\mathrm{T}_{\mathrm{b} 1}, \mathrm{~T}_{\mathrm{b} 4}, \mathrm{~T}_{\mathrm{b} 7}, \mathrm{~T}_{\mathrm{b} 10}$ & Type K Thermocouple \\
\hline Midpoint Bed Temperatures, ${ }^{\circ} \mathrm{C}$ & $\mathrm{T}_{\mathrm{b} 2}, \mathrm{~T}_{\mathrm{b} 5}, \mathrm{~T}_{\mathrm{b} 8}, \mathrm{~T}_{\mathrm{b} 11}$ & Type K Thermocouple \\
\hline Outlet Bed Temperatures, ${ }^{\circ} \mathrm{C}$ & $\mathrm{T}_{\mathrm{b} 3}, \mathrm{~T}_{\mathrm{b} 6}, \mathrm{~T}_{\mathrm{b} 9}, \mathrm{~T}_{\mathrm{b} 12}$ & Type K Thermocouple \\
\hline Outlet Temperature, ${ }^{\circ} \mathrm{C}$ & $\mathrm{T}_{\mathrm{o}}$ & Type K Thermocouple \\
\hline Outlet Pressure, kPa & $\mathrm{P}_{\mathrm{o}}$ & $\begin{array}{l}\text { Capacitance Pressure } \\
\text { Transducer }\end{array}$ \\
\hline Power, W & $P_{e}$ & derived \\
\hline Flow Rate, $\mathrm{kg} / \mathrm{s}$ & $\mathrm{m}$ & derived \\
\hline Specific Power, MJ/kg & $\mathbf{P}_{\mathrm{sp}}$ & derived \\
\hline
\end{tabular}


Table II. Vaporizer Steady Operating Characteristics

$\begin{array}{lcccc}\mathrm{P}_{\mathrm{f}}, \mathrm{kPa} & 682 & 1399 & 2095 & 2770 \\ \mathrm{~m} \times 10^{10}, \mathrm{~kg} / \mathrm{s} & 103 & 159 & 201 & 234 \\ \mathrm{P}_{\mathbf{s p}}, \mathrm{MJ} / \mathrm{kg} & 2.89 & 2.94 & 2.99 & 2.99 \\ \mathrm{P}_{\mathrm{i}}, \mathrm{kPa} & 349 & 556 & 713 & 837 \\ \mathrm{P}_{\mathbf{o}}, \mathrm{kPa} & 209 & 354 & 460 & 548 \\ \mathrm{~T}_{\mathbf{i}},{ }^{\circ} \mathrm{C} & 25 & 25 & 25 & 25 \\ \mathrm{~T}_{\mathbf{o}},{ }^{\circ} \mathrm{C} & 162 & 223 & 260 & 282 \\ \mathrm{~T}_{\mathrm{h}},{ }^{\circ} \mathrm{C} & 184 & 231 & 264 & 293 \\ \mathrm{~T}_{\mathrm{b} 1},{ }^{\circ} \mathrm{C} & 144 & 161 & 170 & 170 \\ \mathrm{~T}_{\mathrm{b} 2},{ }^{\circ} \mathrm{C} & 144 & 161 & 171 & 178 \\ \mathrm{~T}_{\mathrm{b} 3},{ }^{\circ} \mathrm{C} & 142 & 160 & 170 & 177 \\ \mathrm{~T}_{\mathrm{b} 4},{ }^{\circ} \mathrm{C} & 139 & 155 & 163 & 168 \\ \mathrm{~T}_{\mathrm{b} 5},{ }^{\circ} \mathrm{C} & 141 & 159 & 169 & 176 \\ \mathrm{~T}_{\mathrm{b} 6},{ }^{\circ} \mathrm{C} & 190 & 257 & 299 & 324 \\ \mathrm{~T}_{\mathrm{b} 7},{ }^{\circ} \mathrm{C} & 134 & 142 & 143 & 139 \\ \mathrm{~T}_{\mathrm{b} 8},{ }^{\circ} \mathrm{C} & 140 & 158 & 167 & 175 \\ \mathrm{~T}_{\mathrm{b} 9},{ }^{\circ} \mathrm{C} & 168 & 212 & 239 & 253 \\ \mathrm{~T}_{\mathrm{b} 10},{ }^{\circ} \mathrm{C} & 140 & 151 & 152 & 147 \\ \mathrm{~T}_{\mathrm{b} 11},{ }^{\circ} \mathrm{C} & 142 & 160 & 170 & 177 \\ \mathrm{~T}_{\mathrm{b} 12},{ }^{\circ} \mathrm{C} & 170 & 226 & 257 & 274\end{array}$




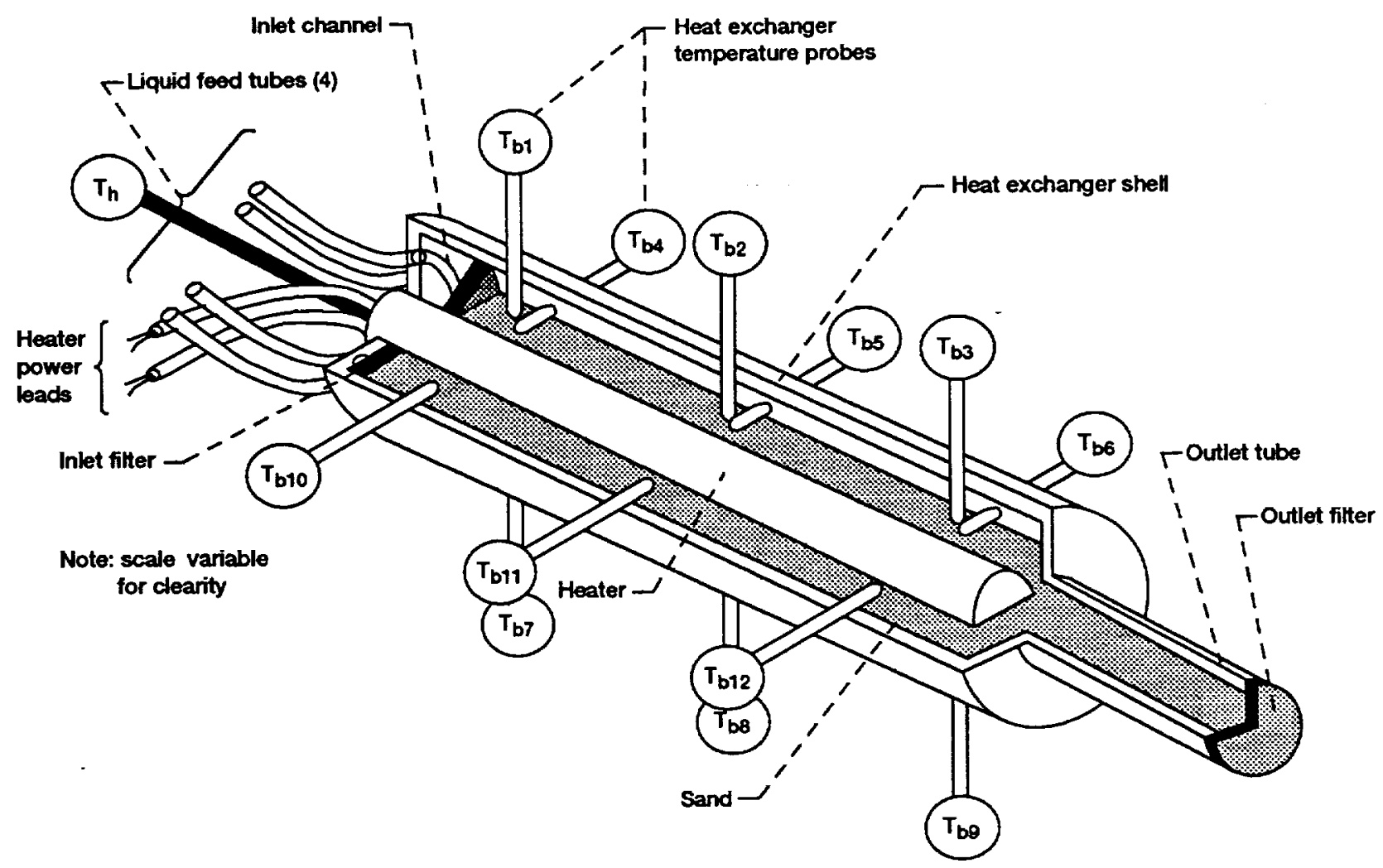

Figure 1.- Sectional view of sand-packed water vaporizer.

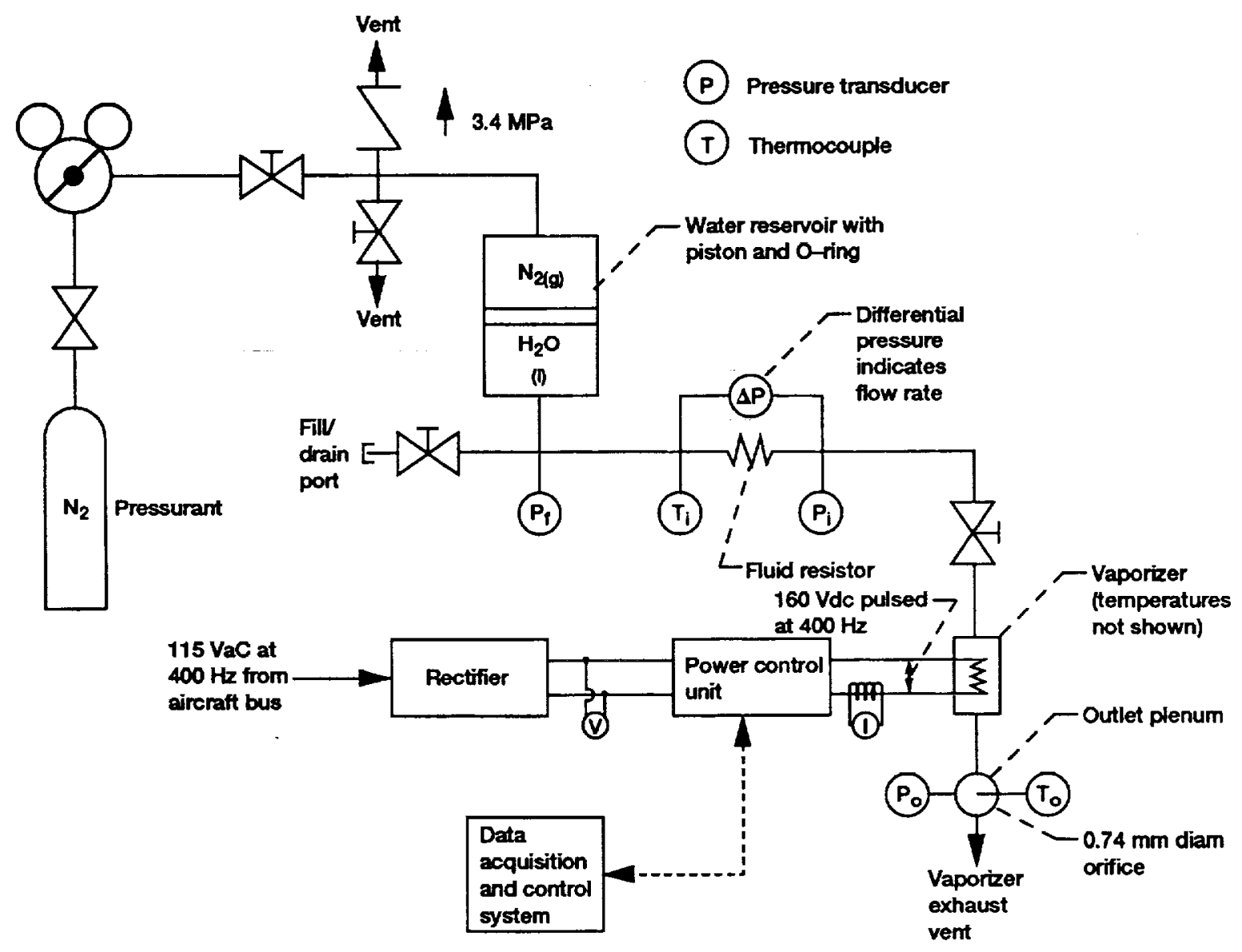

Figure 2.-Water vaporizer test apparatus schematic. 
ORIGINAL PAGE

BLACK ANO WHITE PHOTOGEAPH

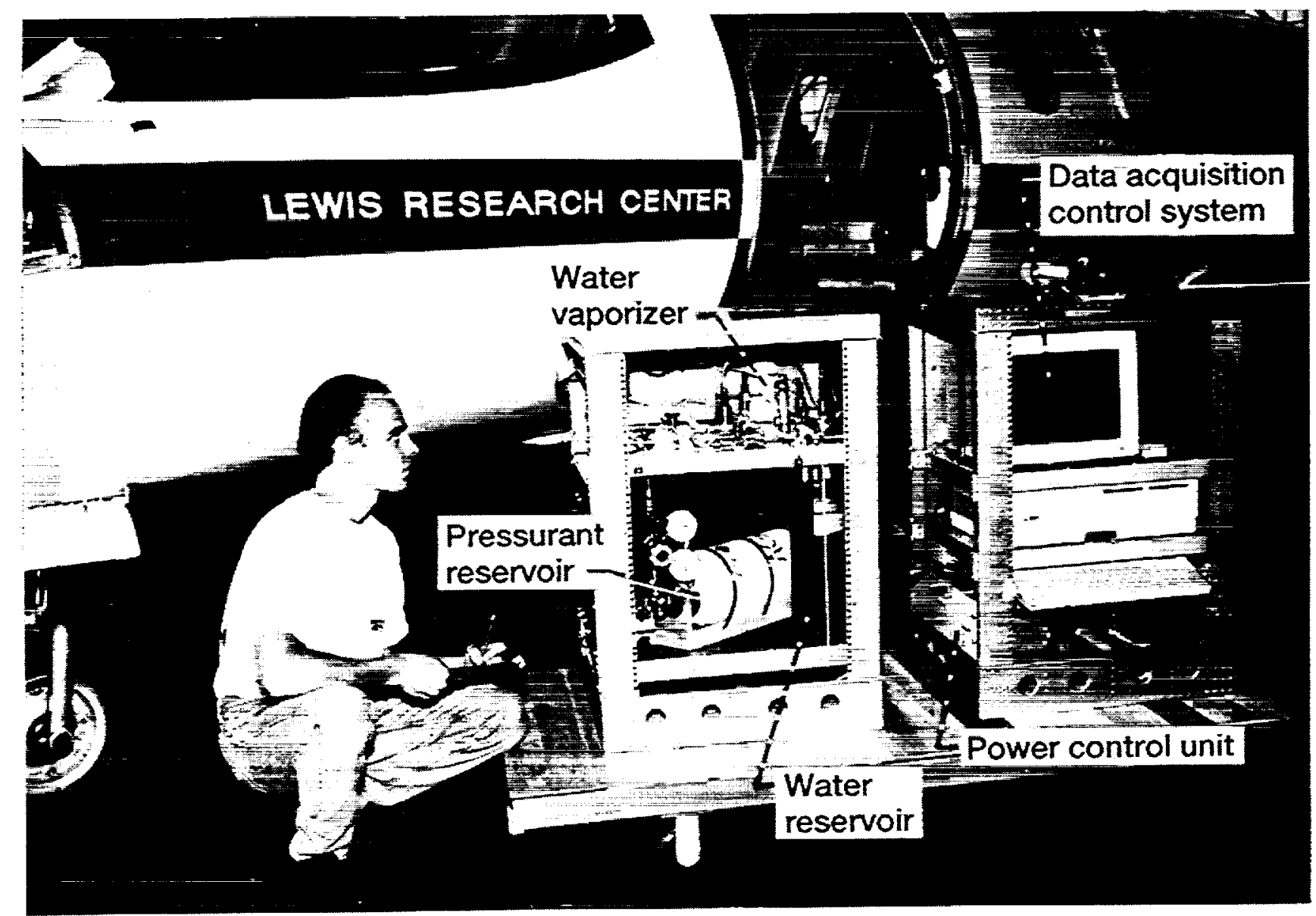

Figure 3.-Water vaporizer test appartus with Lear-Jet low-gravity test aircraft. 


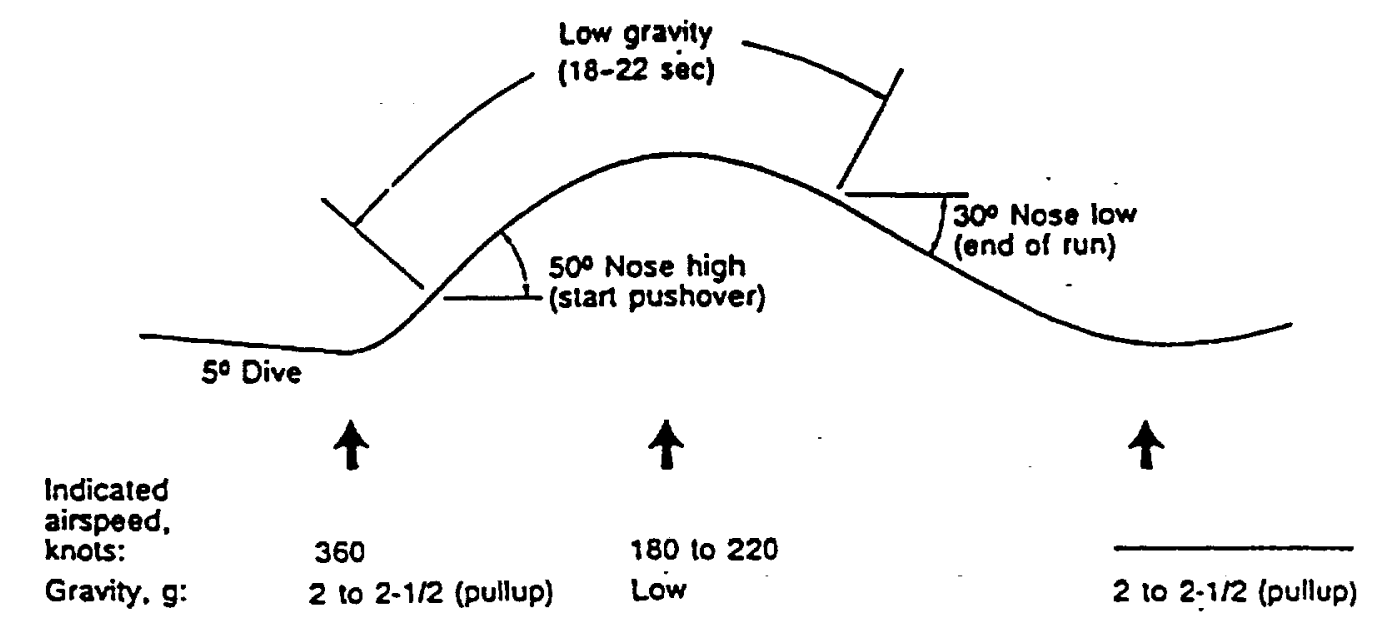

a) Aircraft Flight Path

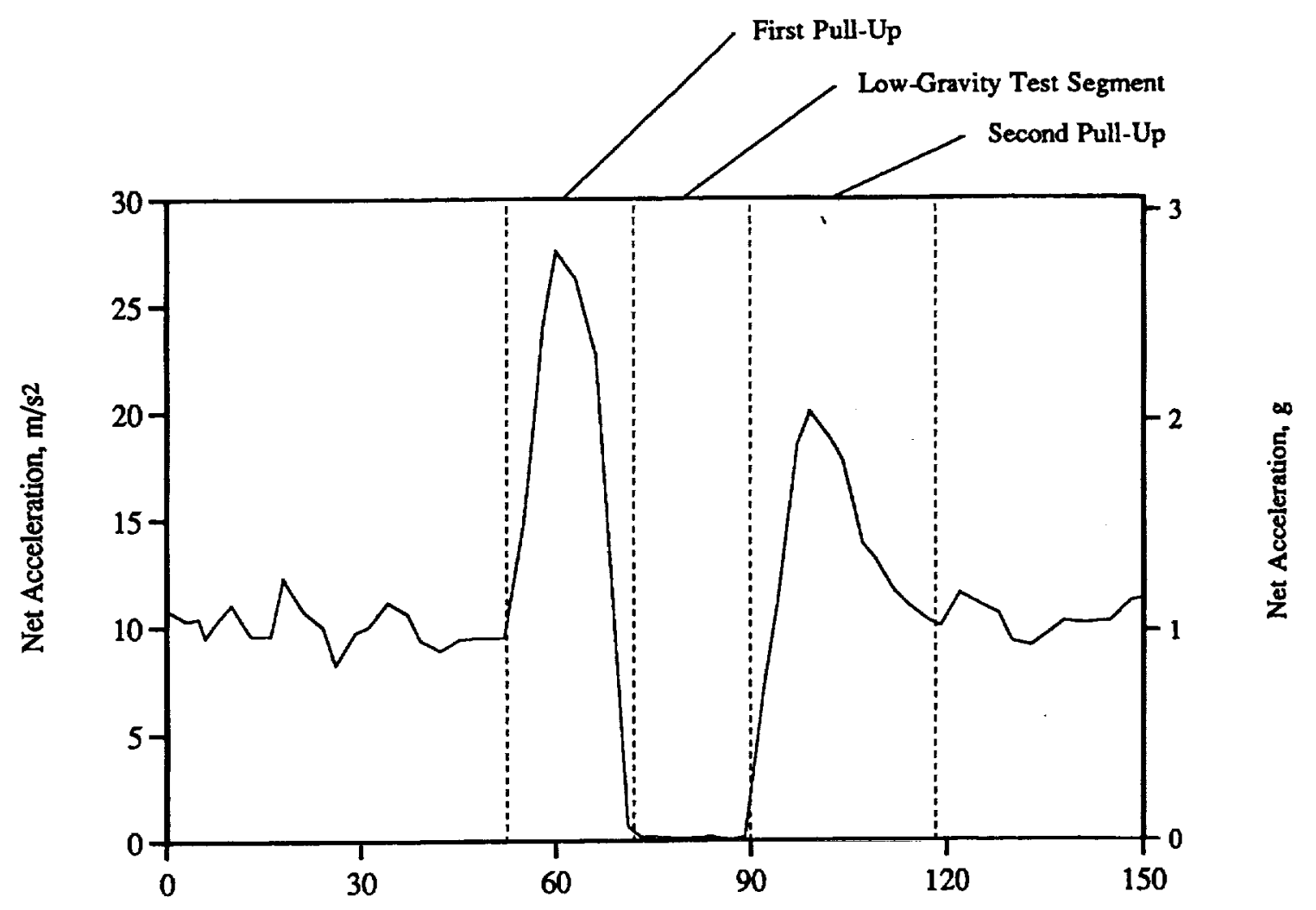

Elapsed Time, $s$

b) Measured Acceleration Profile

Figure 4. Typical Parabolic Trajectory 


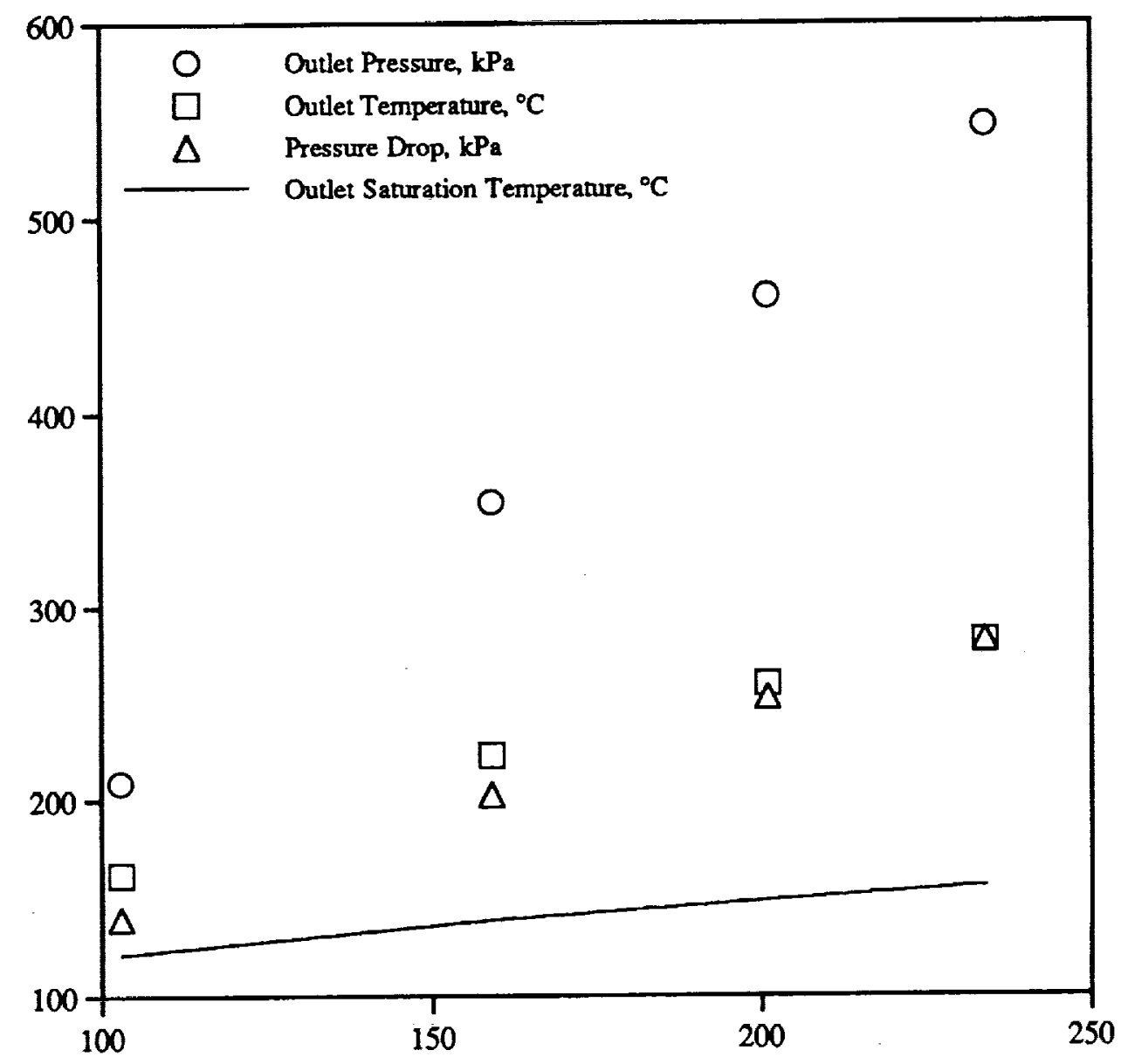

Flow Rate $\times 106, \mathrm{~kg} / \mathrm{s}$

Figure 5. Steady State Water Vaporizer Characteristics 


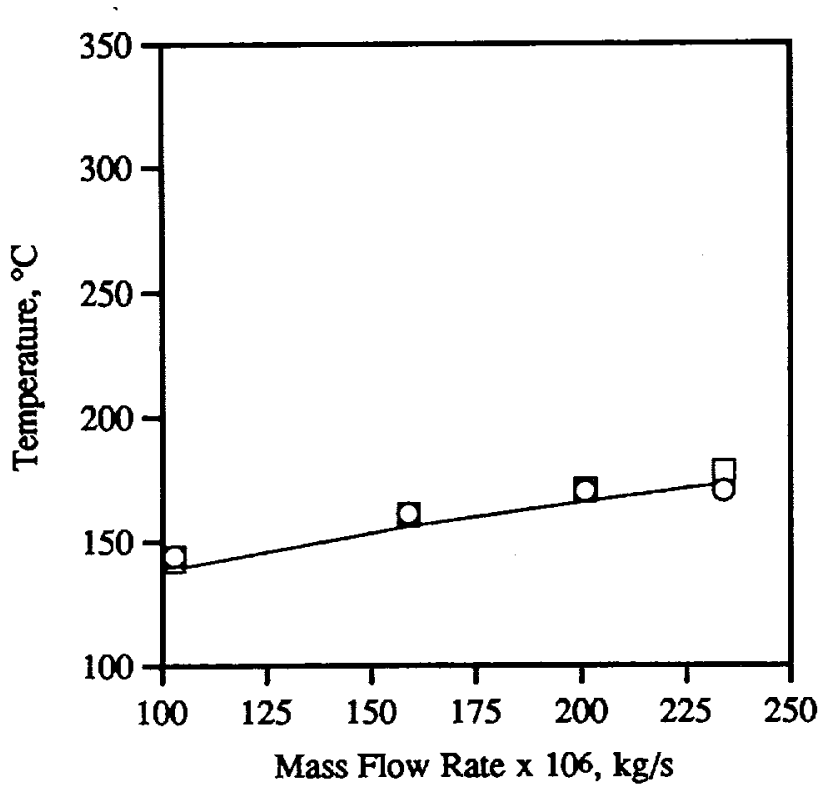

a) Thermocouple Bank \#1 ( $\left.\mathrm{T}_{\mathrm{b} 1}, \mathrm{~T}_{\mathrm{b} 2}, \mathrm{~T}_{\mathrm{b} 3}\right)$

Bed Near Inlet $\left(T_{b 1}, T_{b 4}, T_{b}, T_{b 10}\right) \quad 0$

Bed Near Outlet $\left(\mathrm{T}_{\mathrm{b} 3}, \mathrm{~T}_{\mathrm{bG}}, \mathrm{T}_{\mathrm{b} 9}, \mathrm{~T}_{\mathrm{b} \text { 12 }}\right) \quad \Delta$

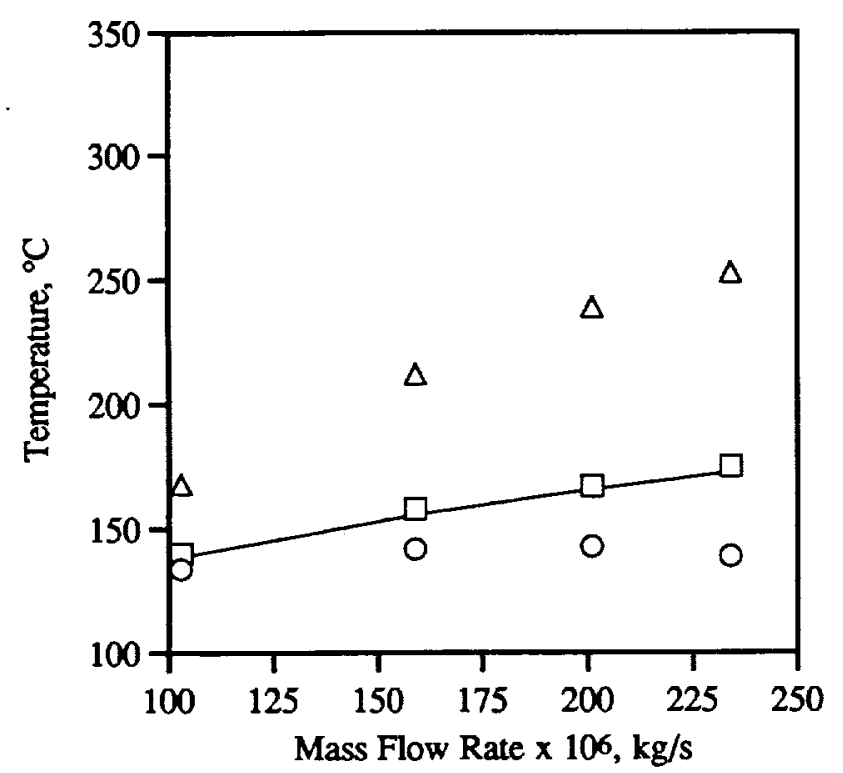

c) Thermocouple Bank \#3 ( $\left.T_{b} 7, T_{b} 8, T_{b} 9\right)$

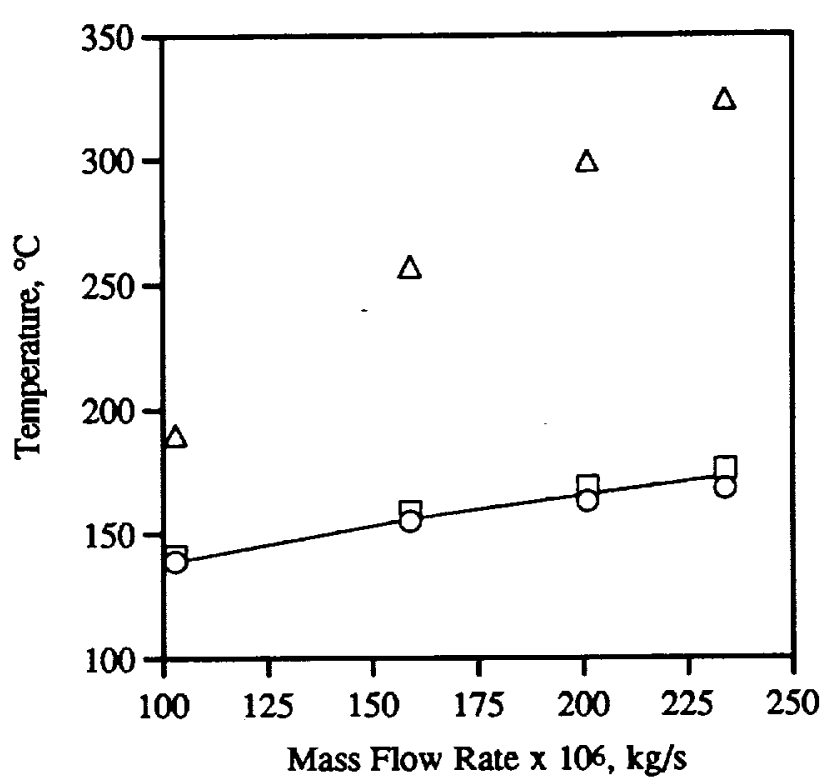

b) Thermocouple Bank \#2 (Tb4, $\left.T_{b 5}, T_{b 6}\right)$
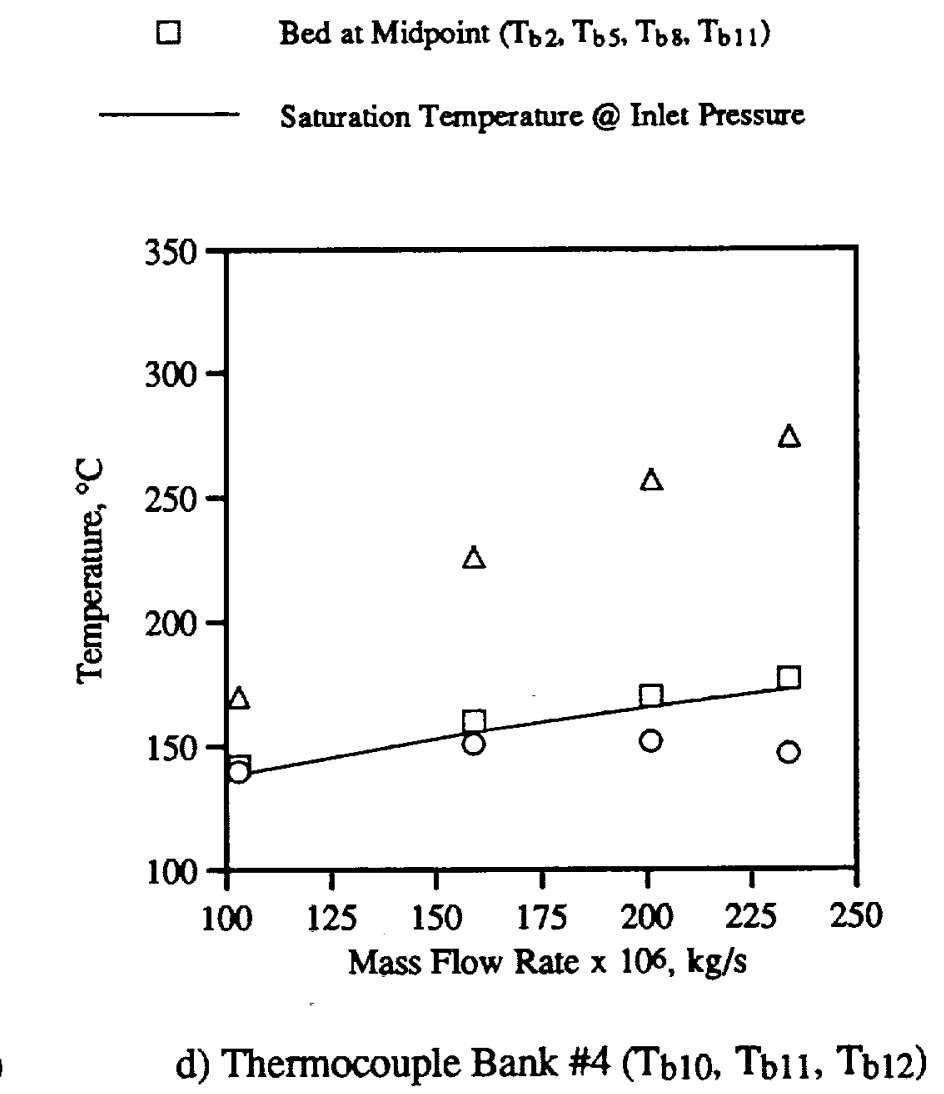

Figure 6. Heat Exchanger Temperature Distributions and

Estimated Saturation Temperatures 


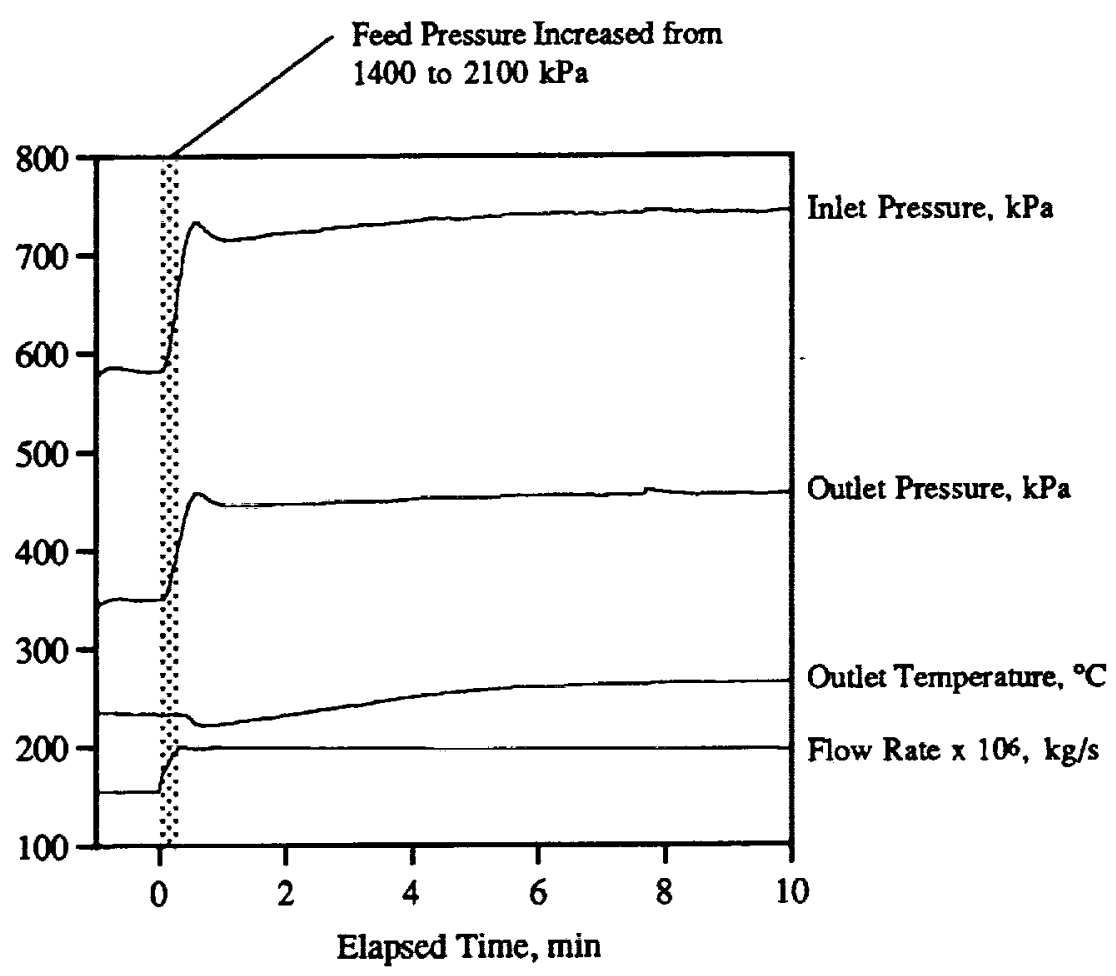

Figure 7. Flow Rate and Inlet and Outlet Condition

Responses to Step Increase in Feed Pressure

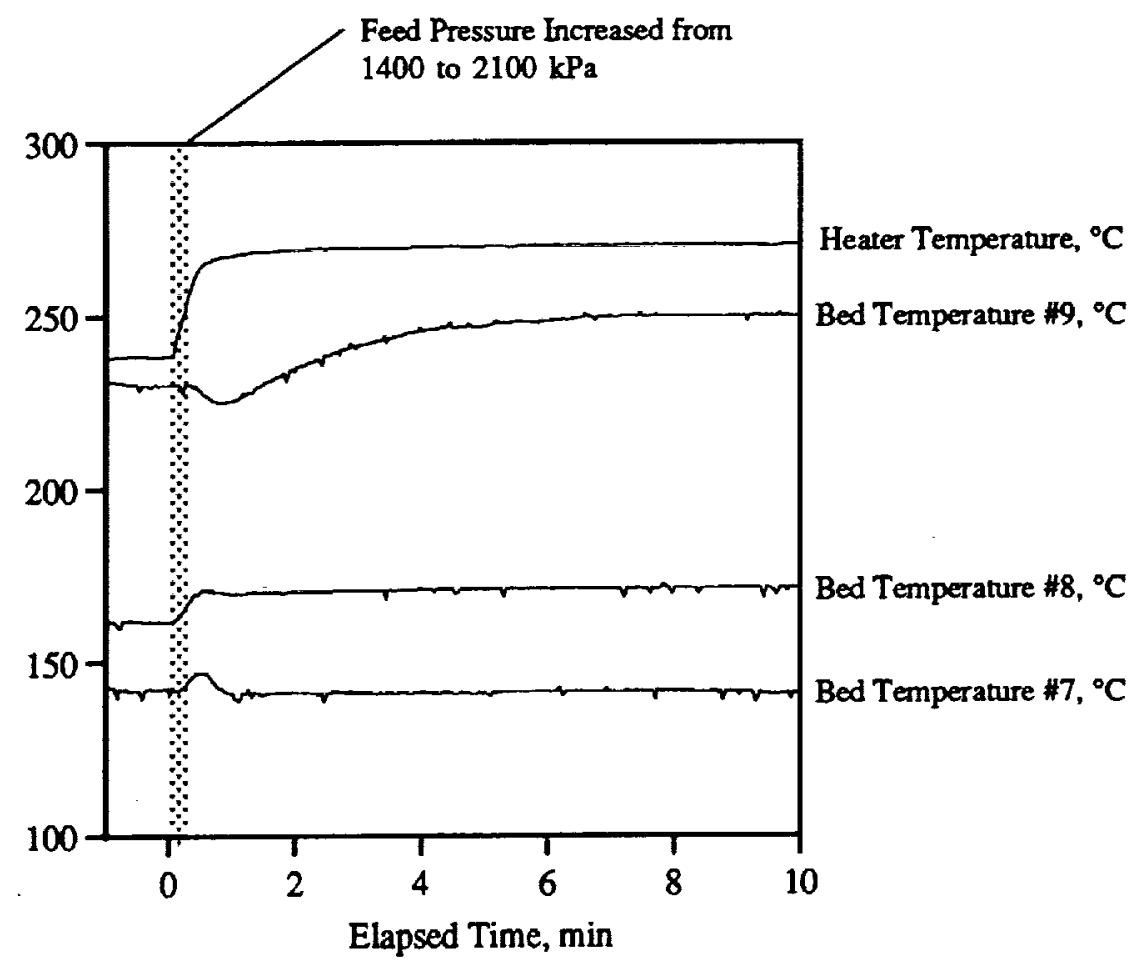

Figure 8. Heater and Heat Exchanger Responses to Step Increase in Feed Pressure 


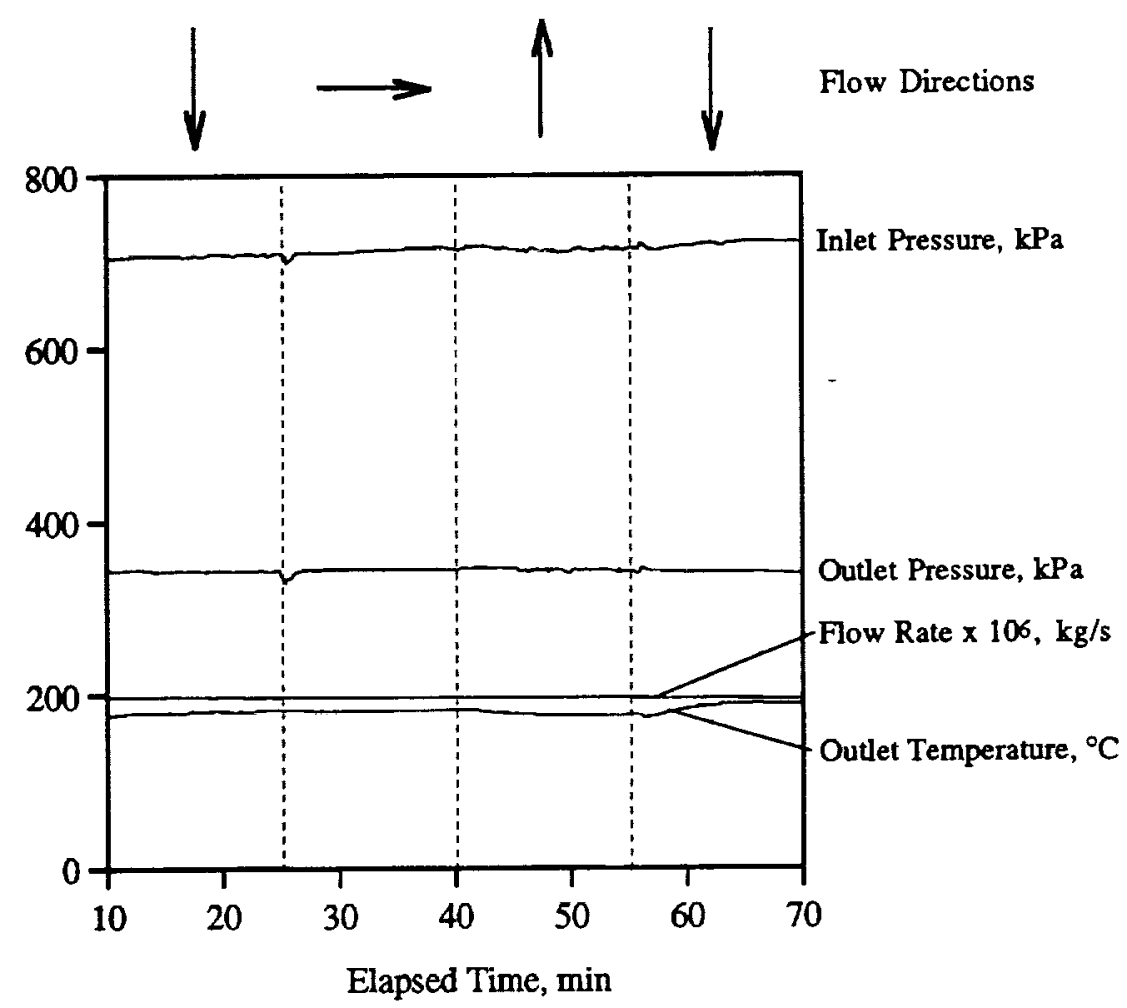

Figure 9. Flow Rate and Inlet and Outlet Condition Sensitivities to Orientation with Respect to Gravity

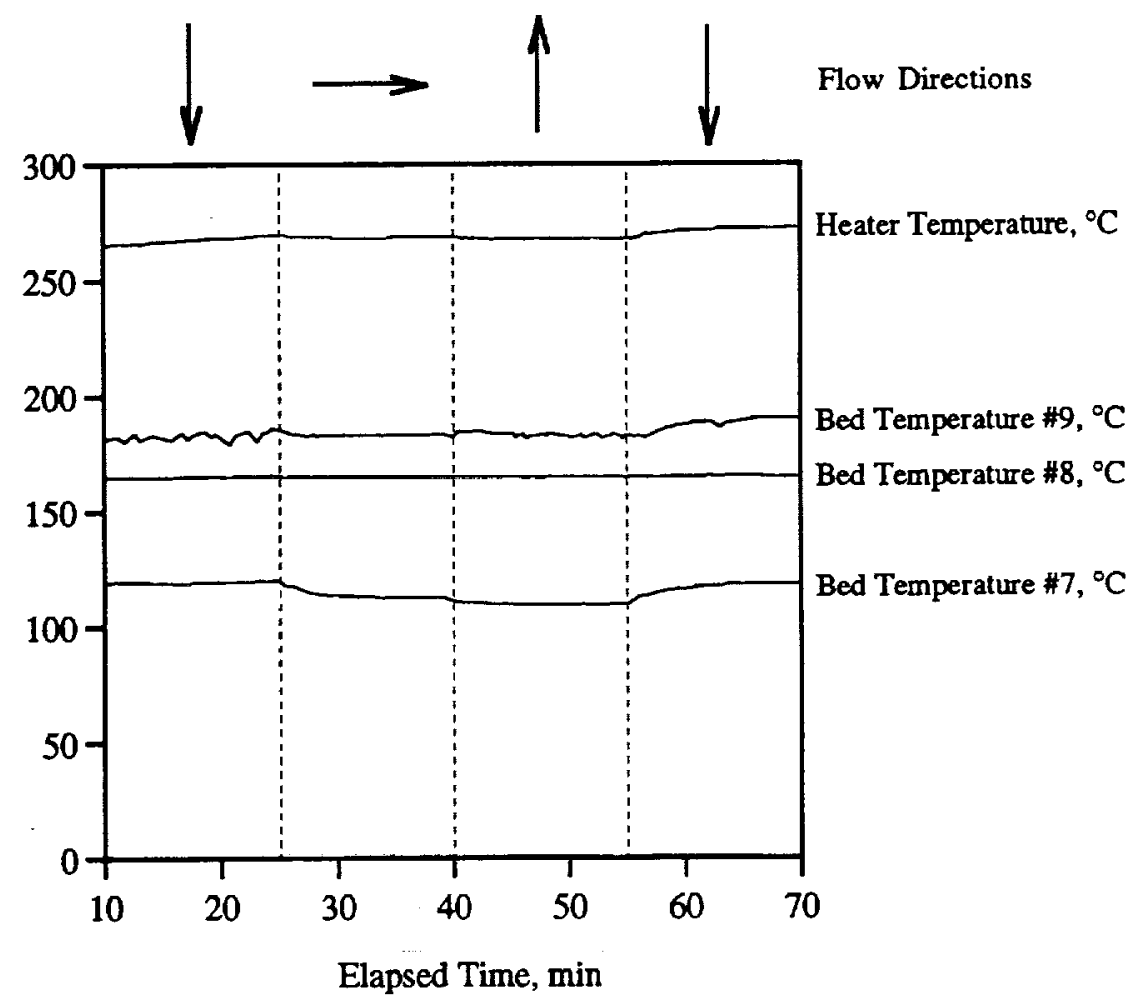

Figure 10. Heater and Heat Exchanger Temperature Sensitivities to Orientation with Respect to Gravity 


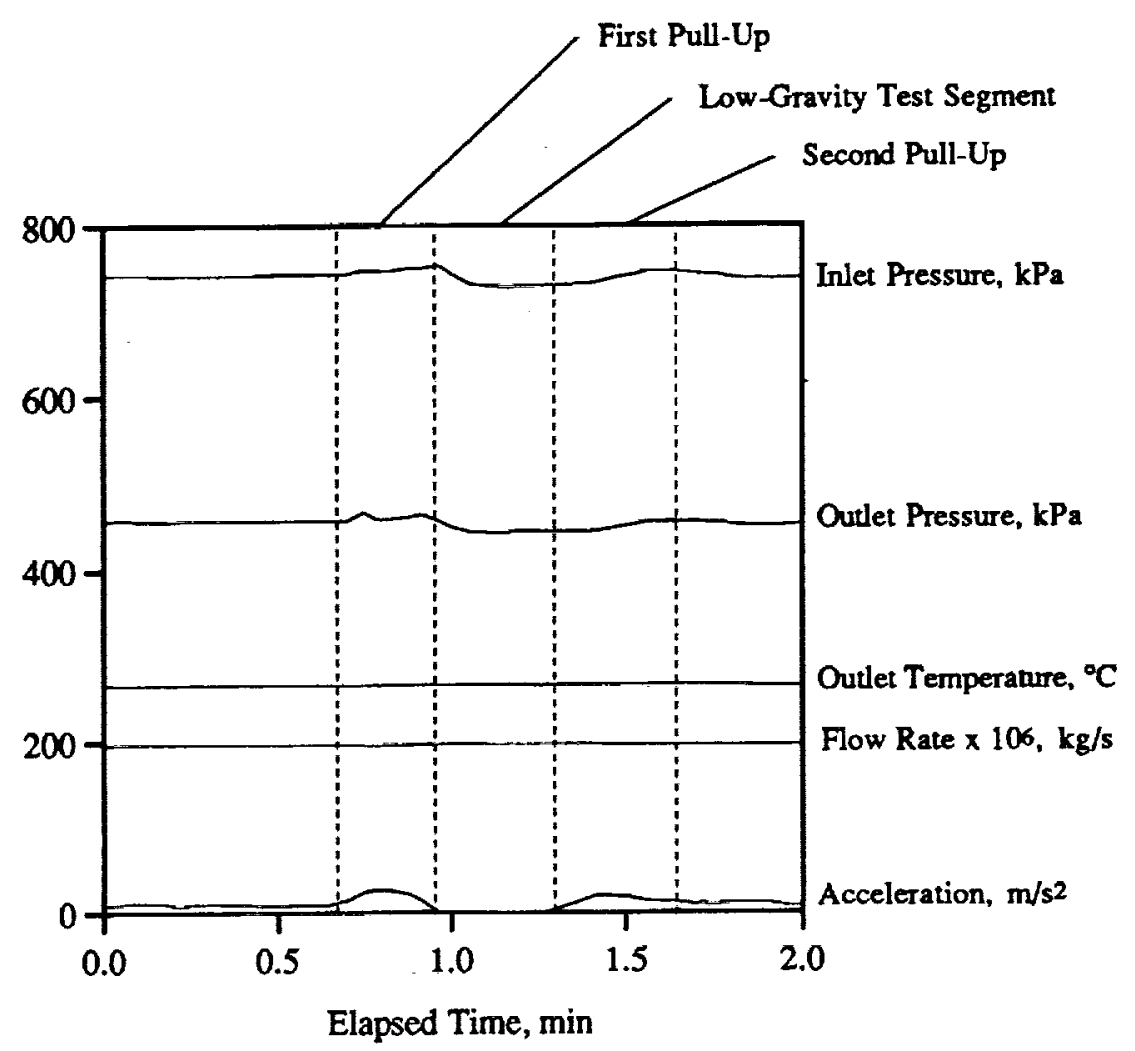

Figure 11. Flow Rate and Inlet and Outlet Condition Sensitivities to Acceleration

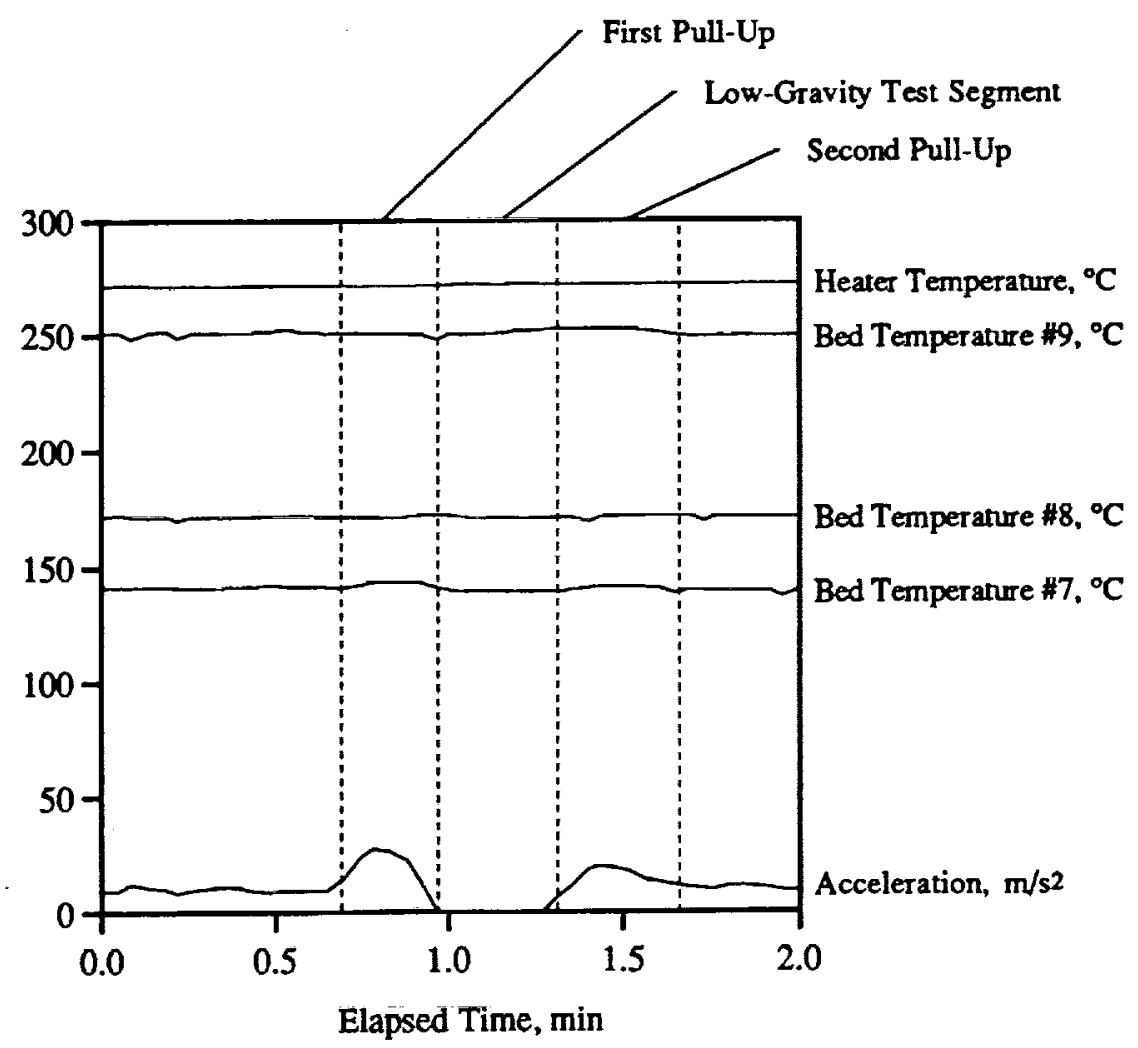

Figure 12. Heater and Heat Exchanger Temperature Sensitivities to Acceleration 


\section{REPORT DOCUMENTATION PAGE}

Public reporting burden for this collection of information is estimated to average 1 hour per response. including the time for reviewing instructions, searching existing data sources, gathering and maintaining the data needed, and completing and reviowing the collection of information. Send comments regandhg this burden estimate or any other aspect of this Davis Highway, Sulte 1204, Avington, VA 22202-4302, and to the Otfice of Management and Budget, Papenwork Reduction Project (0704-0188). Washington, DC 20503.

\begin{tabular}{|l|c|c|}
\hline 1. AGENCY USE ONLY (Leave blank) & $\begin{array}{c}\text { 2. REPORT DATE } \\
\text { June } 1993\end{array}$ & $\begin{array}{r}\text { 3. REPORT TYPE AND DATES COVERED } \\
\text { Technical Memorandum }\end{array}$ \\
\hline
\end{tabular}

4. ITLE AND SUBTITLE

Gravity Sensitivity of a Resistojet Water Vaporizer

6. AUTHOR(S)

W. Earl Morren

7. PERforming ORganzation NAmE(S) AND ADDRESS(ES)

National Aeronautics and Space Administration

Lewis Research Center

Cleveland, Ohio 44135-3191

9. SPONSORINGMONTORING AGENCY NAME(S) AND ADDRESS(ES)

National Aeronautics and Space Administration

Washington, D.C. 20546-0001
5. FUNDING NUMBERS

WU-506-42-31

8. PERFORMING ORGANIZATION REPORT NUMBER

E-7870

10. SPONSOAINGMONTTORING AGENCY REPORT NUMBER

NASA TM-106220

AIAA-93-2402

\section{SUPPLEMENTARY NOTES}

Prepared for the 29th Joint Propulsion Conference and Exhibit, cosponsored by the AIAA, SAE, ASME, and ASEE, Monterey, California, June 28-30, 1993. Responsible person, W. Earl Morren, (216) 433-7425.

12.. DISTRIBUTION/AVAILABILTY STATEMENT

Unclassified - Unlimited

Subject Category 20 12b. DISTRIBUTION CODE

\section{ABSTRACT (Maximum 200 words)}

A laboratory model of a water vaporizer for resistojet applications was designed, fabricated, and steady and transient characteristics were measured. Vaporizer operation was not impacted by rotation about a horizontal axis normal to its own. The vaporizer was operated under low and high accelerations aboard a jet aircraft for periods up to $25 \mathrm{~s}$ at flow rates ranging from $159 \times 10^{-6}$ to $230 \times 10^{-6} \mathrm{~kg} / \mathrm{s}$. Slight changes in inlet and outlet pressures and some heat exchanger temperatures were observed during the low-gravity tests. However, the results of these tests indicated probable compatibility of the vaporizer design tested with a low-gravity environment.

\section{SUBJECT TERMS}

Water resistojet; Water vaporizer; Low-thrust propulsion; Electric propulsion; Low-gravity

\begin{tabular}{|c|c|}
\hline $\begin{array}{c}\text { 17. SECURTY CLASSIFICATION } \\
\text { OF REPORT } \\
\text { Unclassified }\end{array}$ & $\begin{array}{c}\text { 18. SECURTY CLASSIFICATION } \\
\text { OF THIS PAGE } \\
\text { Unclassified }\end{array}$ \\
\hline
\end{tabular}

19. SECURTY CLASSIFICATION OF ABSTRACT Unclassified 
